\title{
Factors Associated with Adherence to Antiretroviral Therapy among HIV- Infected Adults in the Gambia
}

Omar Gassama* and Chien-Huei Kao

National Taipei University of Nursing and Health Sciences, Taipei, Taiwan

\begin{abstract}
Background: Expanding access to ART has not stopped the spread of HIV, especially in developing countries. High level of strict adherence to ARV is essential for effective treatment outcomes. Adherence to treatment is particularly important in regions with inadequate resources for treatment and its outcomes. Results of ART adherence studies in Africa are inconsistent. Literature on ART adherence in the Gambia is insufficient for designing effective intervention programs because of limited studies.
\end{abstract}

Purpose of the study: To understand the factors associated with adherence to antiretroviral treatment among HIV-infected adults in The Gambia.

Methodology: A descriptive cross sectional study design was adopted to collect data using a structured adopted, modified, and pretested among 160 consented respondents receiving ART. Adherence was assessed by a self-report 7 days recall period. Respondents who do not missed or delay a dose for $\geq 90$ min were considered adherent.

Results: About $80 \%(n=128)$ were females, while the remaining $20 \%(n=32)$ were males. Their ages ranged from 18 to 68 years with a mean age of 42.95 . About $88.8 \%(n=142)$ of the respondents reported adhering to their treatment. The majority $82.5 \%$ ( $n=132$ ) of the respondents had a good knowledge score of $\geq 70.0 \%$. The most common reported reasons for missing ART doses include: "Travelled without medication", "Medications finished while on travel", and " Fell asleep /slept through dose time". Knowledge about ART score and HIV treatment regimen were found significantly associated with adherence, with corresponding $p$-values of 0.011 and $<0.001$ respectively. Binary logistic regression identified only knowledge about ART as a factor that influences adherence to ART (odds ratio $=3.463, p=0.025$ ).

Conclusion: The level of adherence to ART in this study is suboptimal, requiring devising specific adherence improvement strategies. A mixed method research that targets different centers may be more helpful in identifying the factors influencing adherence.

\section{Keywords: ART; Adherence; HIV-infected; Factors}

\section{Introduction}

HIV infection is an important public health problem that the world has been facing from its discovery in 1981 up to the present. At the end of 2015 , nearly 36.7 million people were living with HIV, while slightly less than half-18.2 million people-were receiving antiretroviral treatment, according to UNAIDS. Although the number of people receiving treatment more than doubled between 2010 to 2015 (from 7.5 to 18.2 million), infections also increased over that period (from 15.8 million to 36.7 million) [1]. Thus the proportion of people with HIV receiving treatment did not stop the spread of the disease despite the efforts of rapidly expanding access to treatment especially in the developing countries.

There are reports of new HIV infections all over the world, but about two-thirds of these are in Sub-Saharan Africa, with nearly half of all the new cases $(43 \%)$ in Eastern and Southern Africa [1,2]. Access to ARV treatment has contributed significantly to the $40 \%$ decrease in the world's new HIV infections between 1997 and 2015 (from 3.5 million to 2.1 million). Also over 270,000 new HIV infections were prevented between 1990 and 2016 through interventions administered in the Prevention of Mother-to-Child Transmission (PMTCT) programs [3].

There is an ongoing commitment globally by WHO and its partners to combat the epidemic of HIV/AIDS through initiatives, providing and or supporting antiretroviral treatment, which has led to the rapid expansion of access to treatment in developing countries across the world. One such commitment is the 90-90-90 strategy which aims at providing treatment for all HIV-infected, and also ending the global burden of HIV/AIDS by the year 2030. This important strategy targeted: 90 of all people living with the HIV virus knowing their status, $90 \%$ of all confirmed HIVinfected patients obtain continued antiretroviral treatment, and $90 \%$ of all receiving antiretroviral treatment to achieve suppression of the virus [4] The introduction of antiretroviral (ARV) drugs over the last two decades has helped greatly towards controlling the HIV/AIDS infection outcome. Globally, AIDS-related deaths have decreased slightly more than onequarter (from 1.5 million in 2013 to 1.1 million in 2015) [5]. Sub-Saharan Africa accounted for about three-quarters all AIDS-related deaths in the world in 2013 (70\%, 25.6 million), despite efforts to increase access to the antiretroviral treatment over the decade [6].

The Gambia, as part of Sub-Saharan Africa is not an exception to this epidemic of HIV. Since the first case of HIV was discovered in the Gambia in May 1986, there has been a persistent increase in the prevalence of the disease. A report from the first ever Demographic and Health Survey (DHS) conducted in the Gambia in 2013, found that HIV

${ }^{*}$ Corresponding author: Omar Gassama, National Taipei University of Nursing and Health Sciences Nursing, No. 365 Mingde Road, Beitou District 112 Taipei, Taiwan; Tel: +886966752705; E-mail: omsgassama@gmail.com

Received July 04, 2018; Accepted July 17, 2018; Published July 23, 2018

Citation: Gassama O, Kao CH (2018) Factors Associated with Adherence to Antiretroviral Therapy among HIV-Infected Adults in the Gambia. J AIDS Clin Res 9: 771. doi: 10.4172/2155-6113.1000771

Copyright: (c) 2018 Gassama O, et al. This is an open-access article distributed under the terms of the Creative Commons Attribution License, which permits unrestricted use, distribution, and reproduction in any medium, provided the original author and source are credited. 
prevalence was $1.9 \%$ among those $15-49$ years in the general population [7]. At $2.1 \%$, the prevalence was reported to be higher among females, compared to males, at $1.7 \%$. However, there was also a $14.5 \%$ increase in the numbers of persons with HIV on ART over a one-year period, up from 4,006 in 2013 to 4,584 in 2014 [8]. Although the number of people treated is expanding, the death remains high. Specifically, a WHO report indicated that HIV/AIDS is among the top 20 leading causes of death in the Gambia, with the number of total deaths reaching 1,007 or $6.78 \%$ in 2017 . That puts the country at \#25 in AIDS-related deaths worldwide [9]. In response to mitigate the burden of HIV in the Gambia, the national strategic plan as outline in the Gambia National HIV/AIDS policy 2014-2020 aimed to stop and reverse the prevalence of HIV in the Gambia. The policy outlined four important strategies which include: prevention of new infections, minimizing HIV/ AIDS related morbidity and mortality, alleviating the consequence of the disease, and enhancing the efficiency and effectiveness of HIV treatment and control interventions [10].

According to the literature, a strict adherence level of $\geq 95 \%$ is essential for effective treatment outcomes [11]. Lack of strict adherence to ART, in particular, can lead not only to deterioration in clients' clinical condition and well being, but also to developing viruses resistant to the drug. Adherence to treatment is an important component in the success of any ART intervention program, but it is also a common problem for any long term therapy. Systematic reviews, such as one by Scheacher, have reported that adherence to ART ranged from $55 \%$ developed countries to $77 \%$ in developing countries. The review did not offer clear reasons for this poor adherence, but generally, the causes of poor adherence vary and include patient challenges related to age, health literacy, psychosocial and neuro-cognitive issues, and substance abuse, among other factors [12]. Many studies have found that there is still sub-optimal adherence to antiretroviral treatment in Africa.

Adherence to treatment is particularly important in regions where the resources required for treatment and monitoring outcomes are scarce or inadequate, such as in underdeveloped countries. The Gambia is not exceptional in this regard, since it is a developing country with a very fragile healthcare system that, at most levels, lacks adequate capacity and or resources to effectively monitor ARV treatment outcomes. Viral load testing, which is the gold standard for monitoring response to ARV drugs in order to detect early treatment failures, is not routinely available for all patients receiving ART in the Gambia. As such, health care providers rely heavily on clinical and immunological monitoring, such as CD4 count, to track response to therapy. Partial adherence to ART is a particular problem in countries that do not have the capacity to monitor drug resistance and where second-line treatments are not affordable or scarce [13]. An effective individual treatment and community prevention requires understanding both the extent of poor adherence and the factors associated with it [14].

Previous studies have identified barriers to successful adherence that include sociodemographic, cultural, psychological, economic and health care systems related factors [15]. Results of studies of adherence to ART and factors that influence it in Africa are inconsistent, not only between countries, but even within countries and within settings. Studies also do not agree about the determinants of adherence, therefore each region or country needs to identify obstacles to successful implementation of effective and efficient ART intervention programs.

However, literature on ARV treatment adherence in the Gambia is insufficient for designing effective intervention programs. A study conducted at the Medical Research Council's Genitourinary Medicine Clinic in Fajara, the Gambia sought to detect correlations between educational and sociodemographic characteristics and ART adherence. The findings of that study suggest literacy and formal education are beneficial for ART adherence, but the study was not designed to show which of these produced the benefit or to provide an explanatory mechanism [16]. Other factors influencing adherence to ART have not been comprehensively investigated, and this has created a knowledge gap that must be filled in order to strengthen our existing ARV treatment programs.

\section{Materials and Methods}

A conceptual Framework developed based on the WHO's five sets of factors termed dimensions for medication adherence in older adults, and also based on the findings of the literature review guided this study. The components of this framework for factors of adherence to ART include: Knowledge about ART, Demographic factors, medication and related factors, system factors, and community related factors.

A descriptive cross sectional study design was adopted to collect data using a structured questionnaire with face-to-face interviews of the respondents to identify the factors associated with adherence to antiretroviral therapy among HIV-infected adults in the Gambia. The study was conducted at the Hands on Care Clinic in Brikama, West Coast region of the Gambia. Hands on Care is a charitable organization founded in the Gambia in 1999 in response to the sexual and reproductive needs of the community. They provide treatment, care and support for people living with HIV, including antiretroviral therapy [17]. The Clinic is located in the centre of Brikama town, which is 30 kilometers from Banjul, the capital city of the Gambia. Brikama is one of the largest and densely populated towns in the Gambia, with a population of about 70,000.

In order to obtain reliable answers to this study from the respondents, only people living with HIV and are 18 years or older were included. They must be on ART for at least 3 months. They were excluded if they are severely ill, having a mental disorder, or being admitted.

A convenience sampling technique was adopted to select the study participants. All patients that report to the clinic for follow up medication refill and have met the inclusion criteria were approached for participation in the study. The sample size was estimated based on multiple linear regression with 17 independent variables took into account using $G^{*}$ Power 3.1.2 version and considering $10 \%$ dropout rate or attrition rate.

The researcher adapted and modified a combination of two different questionnaires, namely Questionnaire for the Assessment of ART Adherence from Eastern Ethiopia by Letta et al., 2015, and Self-Report Adherence Assessment Questionnaire from Bayelsa State Nigeria by Suleiman \& Momo, 2016, to suit the purpose of this study. The questionnaire is divided into six sections or parts; namely demographic information, knowledge about ART, adherence, medication and related factors, system factors, and community factors. It comprises of thirtysix (36) items.

Five (5) experts having vast knowledge about HIV/AIDS care, treatment, and support were consulted to validate the contents of the tool. One of the experts is from the National Taipei University of Nursing and Health Sciences, while the remaining four are from the Gambia. These experts from the Gambia are senior health care workers with vast years of working experience in the HIV treatment program in the Gambia. A four (4) point Likert Scale was used in the validation of this instrument intended to collect data for this study. The scale had a Content Validity Index (CVI) of greater than 0.80 . Items that do not 
meet the required item-level confidence interval (I-CVI) of 0.80 were either eliminated or slightly modified based on the expert opinion. To ensure reliability of the tool, a pilot study was conducted among the $5 \%$ $(n=8)$ of the total sample size before the commencement of this study.

Data was collected from the study respondents through administration of an adapted, modified, and pre-tested questionnaire in the months of July to September, 2017 by the researcher himself. Participants were recruited at the clinic in a private room during their follow up visit for medication refills, following an informed consent. The questionnaire was self administered for those who can read and understand, whereas those who cannot read, the questionnaire was interpreted to them in the local language that they understand in a faceto-face interview with the researcher. The researcher being fluent in the two most common languages spoken in Western II Health Region: Mandinka, and Wollof.

All the forms were counter checked on site of data collection to ensure completeness. Data was first entered into the excel to easily detect any missing or incorrect data before transposing it to IBM SPSS for analysis. IBM SPSS free trial version was used for the analysis, descriptive statistics were used to present the levels of distribution of the studied variables as frequencies, means, percentages, and standard deviations and presented in the form of tables, charts and figures. Analysis of the dependent variable adherence and its associated factors was conducted using Chi-square test, two-proportion t-test, and binary logistic regression for determining the factors associated with adherence, and $\mathrm{p}<0.05$ considered significant.

Ethical approval was obtained from the University of the Gambia Research and Ethics Committee, before the commencement of the study (\#R017 017v2:). Permission to conduct the study was also obtained from the Director of Hands on Care Clinic in Brikama.

\section{Results}

Demographic characteristics of the study respondents and its relationship with adherence to antiretroviral therapy

A total of $178 \mathrm{HIV}$-infected patients were consulted for participation in this study. A convenient sample of 160 was recruited into this study from July to September 2017 at the Hands on Care Clinic in Brikama. The number of patients declined to participate in the study was 18 , giving us a response rate of about $89.9 \%$. Table 1 shows the demographic characteristics of the study respondents and its relationship with adherence to antiretroviral therapy. The demographic factors considered in this study include age, sex, marital status, employment, and level of education. Out of this total study respondents, $20 \%(n=32)$ were males, their ages ranged from 18 to 68 years with a mean age of 42.95 ( $\mathrm{SD}=10.272)$, slightly more than one-third, $34.4 \%(\mathrm{n}=55)$ were at the ages of 18 to 39 , more than two-third of the respondents, $68.8 \%$ $(\mathrm{n}=110)$ were married at the time of the interview, about two-third, $67.5 \%(n=108)$ were employed, less than half of the study participants, and $40.6 \%(n=65)$ received a degree of formal education.

Eighty-eight percent $(n=142)$ of the respondents reported to have not missed or delay any of their dose in the last seven days prior to the interview.

\section{Knowledge scores about ART and their association with ad- herence to antiretroviral therapy}

Table 2 shows the knowledge scores about ART and their association with adherence to antiretroviral therapy among the study respondents. Knowledge about ART in this study is the extent of understanding about antiretroviral therapy. This includes the mode of action of the ARV drugs, duration of treatment, side effects, and storage of drugs. The great majority of the respondents, $82.5 \%(n=132)$ had a good knowledge about ART 7 of 7 to 10 points. Most of the respondents, 91.9\% ( $\mathrm{n=147)}$ knew that HIV drugs are taken for life, nearly twothirds $65.0 \%(n=104)$, reported that traditional medicine can cure HIV, and close to two-third of the respondents $63.1(\mathrm{n}=101)$, had correctly responded to the statement, in case of a missed dose, one should wait for the next dose.

The association between adherence and medication and related factors, system factors, and community factors

Table $3 \mathrm{~A}$ and Table $3 \mathrm{~B}$ shows the association between adherence and medication and related factors, system factors, and community factors. Medication and related in this study include the medication

\begin{tabular}{|c|c|c|c|c|c|c|c|}
\hline Variables & $\begin{array}{c}\text { Total } \\
N(\%) \\
160(100)\end{array}$ & $\begin{array}{c}\text { Adherent } \\
n(\%) \\
142(88.8)\end{array}$ & $\begin{array}{c}\text { Non-adherent } \\
n(\%) \\
18(11.2)\end{array}$ & Mean & SD & $x^{2}$ & $\mathbf{p}$ \\
\hline \multicolumn{8}{|l|}{ Sex } \\
\hline Male & $32(20)$ & $30(21.1)$ & $2(11.1)$ & & & 1.002 & .317 \\
\hline Female & $128(80)$ & $112(78.9)$ & $16(88.9)$ & & & & \\
\hline Age & & & & 42.95 & 10.272 & & \\
\hline$<40$ years & $55(34.4)$ & $47(33.1)$ & $8(44.4)$ & & & .912 & .340 \\
\hline$\geq 40$ years & $105(65.6)$ & $95(66.1)$ & $10(55.6)$ & & & & \\
\hline \multicolumn{8}{|l|}{ Marital Status } \\
\hline Currently married & $110(68.8)$ & $100(70.4)$ & $10(55.6)$ & & & 1.643 & .200 \\
\hline Currently single ${ }^{a}$ & $50(31.2)$ & $42(29.6)$ & $8(44.4)$ & & & & \\
\hline \multicolumn{8}{|l|}{ Employment } \\
\hline Employed $^{\mathrm{b}}$ & $108(67.5)$ & $98(69.0)$ & $10(55.6)$ & & & 1.319 & .251 \\
\hline Unemployed & $52(32.5)$ & $44(31.0)$ & $8(44.4)$ & & & & \\
\hline \multicolumn{8}{|l|}{ Level of Education } \\
\hline Formal education $^{c}$ & $65(40.6)$ & $56(39.4)$ & $9(50.0)$ & & & .739 & .390 \\
\hline No Formal education ${ }^{d}$ & $95(59.4)$ & $86(60.6)$ & $9(50.0)$ & & & & \\
\hline
\end{tabular}

Notes: a includes single, divorced and widowed; ${ }^{b}$ includes employed, self employed and employed part-time; ${ }^{c}$ inclues primary, junior secondary school, senior secondary school, and university/polytechnic education; ${ }^{d}$ includes no education and Quranic education

Table 1: Demographic characteristics of the study respondents and its relationship with adherence to antiretroviral therapy. 


\begin{tabular}{|c|c|c|c|c|c|c|}
\hline \multirow[t]{2}{*}{ Item No. } & \multirow[t]{2}{*}{ Statements } & \multicolumn{3}{|c|}{ Correct Responses } & \multirow[t]{2}{*}{$z / x^{2}$} & \multirow[t]{2}{*}{$\mathbf{P}$} \\
\hline & & $\begin{array}{c}\text { Total } \\
N(\%) \\
160(100)\end{array}$ & $\begin{array}{c}\text { Adherent } \\
n(\%) \\
142(80)\end{array}$ & $\begin{array}{c}\text { Non-adherent } \\
n(\%) \\
18(20 \%)\end{array}$ & & \\
\hline 1 & HIV drugs are for curing. & $58(36.2)$ & $57(98.3)$ & $1(1.7)$ & 3.007 & 0.003 \\
\hline 2 & HIV drugs are taken for life. & 147(91.9) & $130(88.4)$ & $17(11.6)$ & 6.375 & $<0.001$ \\
\hline 3 & Missing ART doses leads to disease progression. & $157(98.1)$ & $140(89.2)$ & $17(10.8)$ & 7.526 & $<0.001$ \\
\hline 4 & HIV drugs can prevent mother-to-child transmission. & $148(92.5)$ & 133(89.9) & $15(10.1)$ & 6.786 & $<0.001$ \\
\hline 5 & HIV drugs can cause side effects. & $135(84.4)$ & $119(88.1)$ & 16(11.9) & 5.481 & $<0.001$ \\
\hline 6 & HIV drugs should be kept at room temperature. & $115(71.9)$ & $105(91.3)$ & $10(8.7)$ & 4.823 & $<0.001$ \\
\hline 7 & Traditional medicine can cure HIV. & $104(65.0)$ & $95(91.3)$ & $9(8.7)$ & 4.310 & $<0.001$ \\
\hline 8 & $\begin{array}{l}\text { Unprotected sex whilst missing doses of ART may lead to } \\
\text { transmission of HIV. }\end{array}$ & 148(92.5) & $133(89.9)$ & $15(10.1)$ & 6.786 & $<0.001$ \\
\hline 9 & In case of a missed dose, one should wait for the next dose. & $101(63.1)$ & $94(93.1)$ & $7(6.9)$ & 4.355 & $<0.001$ \\
\hline 10 & Taking HIV drugs causes worsening of the disease. & $148(92.5)$ & 135(91.2) & $13(8.8)$ & 7.122 & $<0.001$ \\
\hline \multicolumn{7}{|l|}{ Total } \\
\hline \multicolumn{2}{|c|}{ Less than 7 = "Poor Knowledge" } & $28(17.5)$ & $21(75.0)$ & $7(25.0)$ & 6.427 & 0.011 \\
\hline \multicolumn{2}{|c|}{7 to 10 " = "Good Knowledge" } & $132(82.5)$ & $121(91.7)$ & $11(8.3)$ & & \\
\hline
\end{tabular}

Abbreviations: HIV: Human Immunodeficiency Virus; ART: Antiretroviral Therapy

Table 2: Knowledge scores about ART and their association with adherence to antiretroviral therapy.

\begin{tabular}{|c|c|c|c|c|c|}
\hline Variables & $\begin{array}{c}\text { Total } \\
\mathrm{N}=160 \\
\text { Frequency }\end{array}$ & $\begin{array}{c}\text { Adherent } \\
n=142 \\
\text { Frequency (\%) }\end{array}$ & $\begin{array}{c}\begin{array}{c}\text { Non-adherent } \\
n=18 \\
\text { Frequency (\%) }\end{array} \\
\end{array}$ & $z / x^{2}$ & $\mathbf{P}$ \\
\hline \multicolumn{6}{|c|}{ 1. Medication and related factors } \\
\hline \multicolumn{6}{|c|}{ HIV drug combination currently taking/Treatment regimen } \\
\hline AZT/3TC/NVP & $34(21.2)$ & 28(19.7) & $6(33.3)$ & 5.990 & $<0.001$ \\
\hline AZT/3TC/EFV & $1(0.6)$ & $1(0.7)$ & $0(0.0)$ & 12.649 & $<0.001$ \\
\hline TDF/3TC/NVP & $3(1.9)$ & $3(2.1)$ & $0(0.0)$ & 12.649 & $<0.001$ \\
\hline TDF/3TC/EFV & $101(63.1)$ & $91(64.1)$ & $10(55.6)$ & 8.184 & $<0.001$ \\
\hline AZT/3TC/LPV/r & $19(11.9)$ & $18(12.7)$ & $1(5.6)$ & 9.911 & $<0.001$ \\
\hline TDF/3TC/LPV/r & 2(1.2) & $1(0.6)$ & $1(5.6)$ & $<0.001$ & 1.000 \\
\hline \multicolumn{6}{|c|}{ No. of pills per day } \\
\hline 1 tablet & 102(63.8) & $92(64.8)$ & $10(55.6)$ & 0.589 & 0.443 \\
\hline$>1$ tablet & $58(36.2)$ & $50(35.2)$ & $8(44.4)$ & & \\
\hline \multicolumn{6}{|c|}{ Duration on current HIV drug combination (months) } \\
\hline$<6$ months & $72(45.0)$ & $64(45.1)$ & $8(44.4)$ & 0.003 & 0.960 \\
\hline$\geq 6$ months & $88(55.0)$ & $78(54.9)$ & $10(55.6)$ & & \\
\hline \multicolumn{6}{|c|}{ Side effects experienced } \\
\hline No & $72(45.0)$ & $67(47.2)$ & $5(27.8)$ & 2.431 & 0.119 \\
\hline Yes & $88(55.0)$ & $75(52.8)$ & $13(72.2)$ & & \\
\hline \multicolumn{6}{|c|}{ Experienced a change of Treatment } \\
\hline No & $57(35.6)$ & $50(35.2)$ & $7(38.9)$ & 0.094 & 0.759 \\
\hline Yes & $103(64.4)$ & $92(64.8)$ & $11(61.1)$ & & \\
\hline \multicolumn{6}{|c|}{$\begin{array}{l}\text { Taking other drugs beside } \\
\text { HIV drugs }\end{array}$} \\
\hline No & $94(58.8)$ & $86(60.6)$ & $8(44.4)$ & 1.713 & 0.191 \\
\hline Yes & $66(41.2)$ & $56(39.4)$ & $10(55.6)$ & & \\
\hline
\end{tabular}

Table 3A: The association between adherence and medication and related factors, system factors, and community factors.

regimen, pill burden, duration on ART, and medication side effects. Whereas the system factors include access to ART and patient-health care provider relationships. And the community factors include the disclosure status of people living with HIV, social support, and stigma.

Most of the respondents, $63.1 \%(n=101)$ were taking TDF/3TC/ $\mathrm{EVF}$, which is a single pill once daily dose regimen and also the firstline treatment regimen for HIV in the Gambia at the time of this study, and adherence to treatment was higher among those taking one pill per day $90.2 \%(n=92)$. The level of adherence is higher in the respondents who have been on HIV drugs for less than 6 months $88.9 \%(n=64), 93.1 \%(n=67)$ for respondents who did not report experiencing any side effects, $89.3 \%(n=92)$ in those who did experience change of treatment, $90.0 \%(n=9)$ for respondents whose mean of transport for follow up visit for medication refill is by foot or animal, and $100.0 \%(n=10)$ for respondents whose average waiting time was 60 or less minutes. In trying to establish the association between the variables analyzed and adherence, the current HIV drug combination regimens showed to have an association with adherence ( $p$-value $<0.001)$, except for the $\mathrm{TDF}+3 \mathrm{TC}+\mathrm{LPV} / \mathrm{r}$ regimen which has a $\mathrm{p}$-value $>0.005$. 


\begin{tabular}{|c|c|c|c|c|c|}
\hline \multicolumn{6}{|l|}{ 2. System Factors } \\
\hline \multicolumn{6}{|l|}{ Means of transport } \\
\hline By walking/animal & $10(6.2)$ & $9(90.0)$ & $1(10.0)$ & 0.017 & 0.897 \\
\hline Public/private transport & $150(93.8)$ & $133(88.7)$ & $17(11.3)$ & & \\
\hline \multicolumn{6}{|c|}{ Distance, time taken (minutes) } \\
\hline$\leq 60$ & $87(54.4)$ & $78(89.7)$ & $9(10.3)$ & 0.157 & 0.692 \\
\hline$>60$ & $73(45.6)$ & $64(87.7)$ & $9(12.3)$ & & \\
\hline \multicolumn{6}{|l|}{ Average waiting time } \\
\hline$\leq 60$ & $10(6.2)$ & $10(100.0)$ & $0(0.0)$ & 0.083 & 0.773 \\
\hline$>60$ & $150(93.8)$ & $132(88.0)$ & $18(12.0)$ & & \\
\hline \multicolumn{6}{|l|}{ 3. Community factors } \\
\hline \multicolumn{6}{|l|}{ Disclosure of HIV status } \\
\hline Yes & $148(92.5)$ & 132(89.2) & $16(10.8)$ & 0.381 & 0.537 \\
\hline No & $12(7.5)$ & $10(83.3)$ & $2(16.7)$ & & \\
\hline \multicolumn{6}{|c|}{ Adherence support from family } \\
\hline Yes & $107(66.9)$ & $97(90.7)$ & $10(9.3)$ & 1.173 & 0.279 \\
\hline No & $53(33.1)$ & $45(84.9)$ & $8(15.1)$ & & \\
\hline \multicolumn{6}{|c|}{ Adherence Support outside family } \\
\hline Yes & $13(8.1)$ & $13(100.0)$ & $0(0.0)$ & 0.320 & 0.572 \\
\hline No & $147(91.9)$ & $129(87.8)$ & $18(12.2)$ & & \\
\hline \multicolumn{6}{|l|}{ Experienced stigma } \\
\hline Yes & 19(11.9) & $17(89.5)$ & $2(10.5)$ & 0.011 & 0.915 \\
\hline No & $141(88.1)$ & $125(88.7)$ & $16(11.3)$ & & \\
\hline
\end{tabular}

Abbreviation: HIV, human immunodeficiency virus

Table 3B: The association between adherence and medication and related factors, health system factors, and community factors.

\section{Factors associated with adherence to antiretroviral therapy}

Table 4 shows the factors associated with adherence to antiretroviral therapy in this study. To understand the factors associated with adherence to antiretroviral therapy among HIV-infected adults, a binary logistic regression was used in the analysis. Only knowledge about ART showed to be significantly associated with adherence to ART having a p-value of 0.025 , odds ratio of 3.463 . The other variables appear to have no significant association with adherence in this study.

\section{Reasons for not adhering to treatment}

Table 5 shows the reasons for not adhering to the ARV medications reported by the study respondents. The common important reasons reported for missing taking the ARV medications include: travelled without medication $38.9 \%(n=7)$, medications finished while on travel $22.2 \%(n=4)$, and fell asleep /slept through dose time $16.7 \%(n=3)$.

\section{Discussion}

The majority of the respondents were females $80 \%(n=128)$. The number of HIV-infections in the Gambia are higher among females compared to the males. Polygamy as accepted by the Islamic religion and most cultures in the Gambia may have also contributed to the high incidence of HIV among women. Other possible explanations could be women having more concern about their health status as their male counterparts or having recruited more females by chance from a convenience sampling method.

Overall, the level of adherence to ART among the respondents was $88.8 \%(n=142)$, although suboptimal considering $\geq 95 \%$ level of adherence required for effective treatment outcome, is still higher than those reported in most studies used in this review. The high level of adherence in this study may have been influenced by the possibility of bias in self-report surveys from social desired response or not accurately reporting the actual doses missed. Another possible explanation of this

\begin{tabular}{|l|c|c|c|c|}
\hline Variables & B & SE & Odds ratio & P \\
\hline Sex & 0.358 & 0.862 & 1.431 & 0.677 \\
\hline Age in years & -0.265 & 0.554 & 0.767 & 0.633 \\
\hline Marital status & -0.661 & 0.550 & 0.516 & 0.229 \\
\hline Employment status & -0.462 & 0.567 & 0.630 & 0.415 \\
\hline Educational status & -0.487 & 0.540 & 1.628 & 0.367 \\
\hline Knowledge about ART & 1.242 & 0.554 & 3.463 & 0.025 \\
\hline Constant & -1.771 & 1.505 & 0.170 & 0.239 \\
\hline
\end{tabular}

Note: *Statistically significant

Abbreviations: ART: Antiretroviral Therapy; SE: Standard Error; B: Coefficient for the constant, $p$ : $p$-value or significance level.

Table 4: Factors associated with adherence to antiretroviral therapy.

\begin{tabular}{|l|c|c|}
\hline Variables & $\begin{array}{c}\text { Frequency } \\
\text { (n) }\end{array}$ & $\begin{array}{c}\text { Percent } \\
\text { (\%) }\end{array}$ \\
\hline Simply forgot & 1 & 5.6 \\
\hline Wanted to avoid the side effects or toxicity of the drug & 2 & 11.1 \\
\hline Fell asleep/slept through dose time & 3 & 16.7 \\
\hline Travelled without medication & 7 & 38.9 \\
\hline Had not eaten food & 1 & 5.6 \\
\hline Medications ran out while travelling & 4 & 22.2 \\
\hline
\end{tabular}

Table 5: Reasons for not adhering to treatment.

high level of adherence could be that, Hands on Care Clinic is one of the best clinics in the Gambia in terms of excellence in providing quality HIV/AIDS care, treatment and support.

The prevalence of non-adhering to ART in this study from the self-report was $11.2 \%(n=18)$. Six reasons were reported by the study respondents as important reasons for missing their ART doses. The most common reason reported by the respondents were "travelled without medication" $38.9 \%(\mathrm{n}=7)$, "medications finished while on travel" 22.2\% ( $n=4)$, and "Fell asleep/slept through dose time" $16.7 \%$ $(\mathrm{n}=3)$. It is not clear whether the respondents deliberately travelled 
without their medications to avoid being noticed by others, or they had transportation difficulties in trying to return back home. Therefore, it will be wise to keep reminding clients on ART to always travel with their medications at all times to avoid missing their doses in case of any unforeseen circumstances. Similar reasons: "travelling out of town", "being away from Home", and "leaving medications at home" was reported by study respondents a reason for missing their doses [18-20]. The second most common reason reported by the respondents for missing their ART doses was "medications finished while on travel" $22.2 \%(\mathrm{n}=4)$ and "Fell asleep/slept through dose time" ranked third common reason for missing ART. This shows the need for travelling with adequate medications to last more than the duration of travel. The need for a reminder in the form of an alarm of a watch or mobile phone, or from a treatment support which could be a partner, friend, or member of the family could be helpful in promoting adherence. "Fell asleep/slept through dose time" and "Not eaten food" were additional reasons our study found as reasons for missing ART doses. Our literature review could not find such important reasons in the studies reviewed. The use of face-to-face interview with the respondents may have contributed to identifying such reasons (Figure 1).

One Gambian study found that $49 \%(n=83)$ of the study respondents reported never missing any dose in the preceding month, and $31 \%$ reported missing between one and three doses in the preceding month [16]. This shows a need for an ongoing counselling on adherence of patients on ART, and also finding out possible barriers to help in promoting their adherence to ART. The different criteria used for assessing adherence in the two studies may have also contributed to the difference in the levels of adherence, seven days and one month recall periods.

Similar findings of level of adherence to ART were reported in other parts of Africa and Hong Kong, 85.0\% to 88.0\% [19,21-23]. Other studies in some other parts of the world found slightly lower levels of adherence to ART, $73.0 \%$ to $78.9 \%$ [20,24-26]. Very low levels of adherence to ART were found in some studies, $25.0 \%$ to $59.9 \%$ $[18,27,28]$.

The differences in the levels of adherence to ART in these studies may be influenced by the different methods and criteria used to measure adherence. The most common method for assessing adherence in this review was self-reports, although several methods, including pill counting, pharmacy refills, and clinical monitoring were used. The recall periods for measuring adherence range from two days to one month, but 7 days recall period were frequently used in most studies [18-20].

\section{Factors Associated with ART Adherence}

The following five variables were investigated for their relationship with adherence to antiretroviral therapy: demographic factors, medication and related factors, system factors, community factors, and knowledge score about ART.

\section{Demographic factors}

The demographic factors investigated in this study include only five variables; sex, age, marital status, employment, and level of education. In this study, the majority of the respondents, $80 \%(n=118)$ were females, which may have an influence on the results. In a Gambian ART adherence study by Hegazi et al. (2010), 61\% were females. The reason for having more females might be that women care more about their health than males or the infection being generally more prevalent among females than male. All the five demographic variables did not show a significant association with adherence to ART among the respondents. This finding is consistent with study a study in South South Nigeria by Oku et al. (2013). However, other studies from parts of Asia have likewise reported a lack of association between demographic variables and adherence to ART $[20,23,24]$.

There are several studies conducted in Africa and other parts of the world that did not support our findings. In the Gambia where this study is conducted, one study has found that literacy and formal education have an association with adherence to ART [16]. The difference in the characteristics of the sample may have contributed to the difference in findings. In that study, only $38 \%(n=56)$ did not have formal education, whereas in our study, slightly more than half the respondents $59.4 \%$ $(n=95)$ did not have formal education. Some studies have found an association between higher levels of education of the respondents and good adherence behavior towards ART $[25,26,28]$. Two Nigeria studies have found an association between sex of the respondents and their adherence to ART [25,27]. Studies conducted in Eastern Ethiopia and Zambia Rural Settings have found its association with adherence and

\section{Reasons for missing ARV medications}

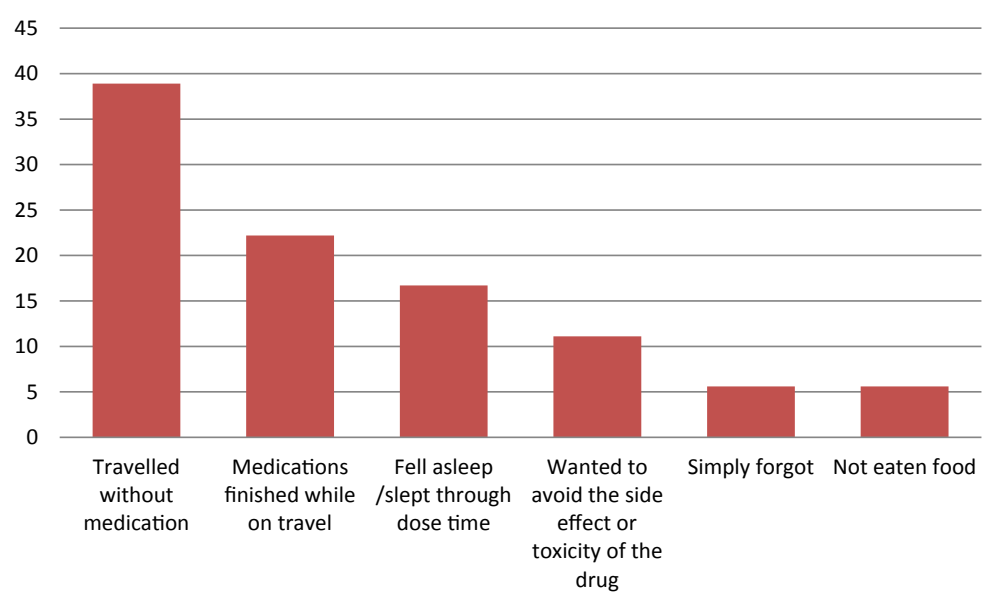

Figure 1: Reasons for missing ARV doses. 
age $[19,22]$. Other studies conducted in Nigeria and Southern Ethiopia found an association between marital status and adherence to ART $[21,25,27]$. In relation to finding an association between employment and adherence to ART, Suleiman and Momo, 2016 found a significant association between occupation of the study respondents and their adherence status.

\section{Medication and related factors}

The findings from this study showed that only the type of HIV drug combination regimen has an association with adherence. This possible explanation of this finding might be that the first-line treatment regimen, TDF+3TC+EVF, is a single daily dose which help promote their adherence, or they might have been on treatment for longer period thus, enable them to develop coping strategies which enhance adherence. The adherence counselling support received by the respondents at the clinic may have also contributed towards improving their adherence since about $100 \%(n=160)$ reported receiving adherence counselling.

This finding is being supported by a study conducted in Bayelsa State, Nigeria, by Suleiman \& Momo (2016), who found a significant association between ART regimen and adherence. There are some study findings from Africa and Asia that are in contrast to our findings $[21,23,26]$. The differences in the methods used to determine adherence may have contributed to this difference. Some studies used shorter recall periods or longer duration criteria for recruiting, while others use added viral load testings to determine adherence. Several studies have found a significant association between pill burden and adherence $[18,19,28]$.

Other studies have also found a significant association between the duration on ART and adherence [20,24,25]. Experiencing side effects was found to be associated with adherence in a study conducted in Hon Kong [23]. Uzochukwu et al. (2009) found that a greater percentage of their study respondents cited experiencing side effects as important reason for missing their ART doses $76.3 \%(n=100)$, although they did not find it significantly associated with adherence.

\section{System factors}

In this study, the findings did not show any association between the system factors and adherence to ART. In relation to having access to treatment, the findings from this study highlighted that the respondents may have possible difficulties in obtaining easy access to treatment. This is manifested by the large number of respondents use private or public transport to get to the clinic $93.8 \%(n=150)$, distance-time taken $>60$ $\min 45.6 \%(n=73)$, and average waiting time $>60 \min 93.8 \%(n=150)$. Difficulty in accessing treatment due to a transportation difficulty was cited in one study as an important reason for the respondents missing their ART doses [20]. In another study, obtaining free ART services was significantly associated with adherence [18].

The study findings showed a good patient-health care provider relationships even though it does not show any significant association. A good patient-health care provider relationship is expected in this study because, about $100 \%(n=160)$ agree that they received adherence counselling support, as well as privacy being maintained during the counselling. In one study, about $51.2 \%(n=21)$ of the respondents who never missed their doses reported obtaining support from health workers helped them to adhere to their treatment [20].

\section{Community factors}

Although some studies found an association between these variables and adherence to ART, this study could not find any significant association. Similar findings are expected in this study as evidenced by the high number of the study respondents having disclosed their HIV Status $92.5 \%(n=148)$, received adherence support from the family $66.9 \%(n=107)$, did not experience stigma $88.1 \%(n=141)$. These are proportionately large number of the respondents who received good support from the community.

Non-disclosure of HIV-status to a family member was associated with poor adherence (Letta et al., 2015; Pahari et al., 2015). Another study in Togo by Yaya et al., (2014), found an association between HIVstatus disclosure to a sexual partner and adherence.

Regarding social support, one study conducted in Highlands of Papua New Guinea found that some respondents who never missed their ART doses reported obtaining support from the family, church, or the community helped them to adhere to their treatment. Experiencing stigma can be associated with poor adherence for people on ART [27].

\section{Knowledge about ART}

A significant association has been found between knowledge about ART and adherence to ART in this study. This finding validates some other studies where peoples' knowledge and or perception about ART had influence on their adherence behavior. A greater percentage of the respondents in this study scored between 7 and 10 which is referred to as having good knowledge $82.5 \%(n=132)$. An explanation of this finding could be that Hands on Care Clinic in Brikama is one of the best outstanding clinics in the Gambia, in terms of providing HIV/AIDS care, treatment and support. Another reason could be the adherence counselling support provided by the clinical staff to the respondents as highlighted by about $100 \%(\mathrm{n}=160)$ of the study respondents.

This study finding is supported by Suleiman by ART adherence studies where where they found a significant association between HIV/ ART related knowledge and good perception of ART and adherence $[25,26]$. In contrast, there was no association found between adherence and perception about ART or knowledge on ART [21,28]. The use of shorter duration recall periods to assess adherence in these studies may have contributed to the difference in the findings.

Even though this study has several strengths, including a reasonably large sample size, a shorter recall period, and use of a modified, adapted and pre-tested questionnaire, there are some limitations as many other studies. Since the study was conducted in one ART center in the Gambia, use of convenient sampling and a moderate sample size are also important weaknesses of this study. Recall bias usually experienced in self-report surveys from social desired responses or errors in reporting correctly, also makes the findings not completely reliable. The results might not be representative of the entire country, and therefore, should be interpreted with caution

Since HIV/AIDS and ART related knowledge were found to influence peoples' adherence behavior towards ART, it is important to have ongoing patient information throughout the course of the treatment. A mass media campaign on HIV/AIDS care, treatment and support is necessary for the general population to reduce the stigma associated with HIV in the society, for patients to be able to have the appropriate support from their friends, families and the entire community. Considering the use of mixed method research involving both qualitative and quantitative approaches can produce more reliable results. The Gambia National AIDS Control Program should should conduct and support ART adherence studies across the entire country to guide the current ART treatment programs. Through consultation 
Citation: Gassama O, Kao CH (2018) Factors Associated with Adherence to Antiretroviral Therapy among HIV-Infected Adults in the Gambia. J AIDS Clin Res 9: 771. doi: 10.4172/2155-6113.1000771

with the partners, The Gambia National AIDS Control Program should provide a unique standard for adherence assessment to guide future research. Considering reestablishing nutritional support program for people living with HIV in the form of food supplementation by the Gambia National AIDS Control Program would be helpful as one of the respondents reported not having food to eat lead to missing a dose.

To provide quality HIV/AIDS care, treatment and support, all healthcare workers involved antiretroviral treatment services should be trained in offering adherence counselling services to patients on ART. Continuous assessment of adherence to ART and devising strategies to promote better adherence behavior in consultation with the patients is highly crucial for successful treatment outcomes.

\section{Acknowledgment}

Special thanks to the Almighty for the accomplishment of this piece of work. And our highest and sincere appreciation to all those who have contributed in one way to this study, especially the staff of the Ministry of Health and Social Welfare the Gambia, National Taipei University of Nursing and Health Sciences, National AIDS Control Program (NACP) the Gambia, and the Infectious Disease Clinic (IDC) of the Edward Francis Small Teaching Hospital, the Gambia. Not forgetting to extend our very special thanks to the director and staff of the Hands On Care clinic in Brikama and the client who took part in this study, for without them, the study would not have been successful.

\section{References}

1. UNAIDS (2018) Factsheet 2017. Latest statistics on the status of the AIDS epidemic.

2. https://www.kff.org/global-health-policy/fact-sheet/the-global-hivaidsepidemic/\#footnote-227337-1

3. https://ourworldindata.org/hiv-aids

4. UNAIDS (2018) 90-90-90 treatment for all: An ambitious treatment target to help end the AIDS epidemic. UNAIDS.

5. http://www.unaids.org/sites/default/files/media_asset/global-AIDSupdate-2016_en.pdf

6. Kharsany AB, Karim QA (2016) HIV infection and AIDS in Sub-Saharan Africa: current status, challenges and opportunities. The open AIDS Journal 10: 34-48.

7. The Gambia Bureau of Statistics (2014) The Gambia demographic and health survey.

8. National AIDS Secretariat (2015) The Gambia global AIDS response progress report. UNAIDS.

9. World Health Organization (2017) World health rankings live longer, live better. WHO.

10. National AIDS Council (2014) National policy guidelines on HIV and AIDS.

11. Chesney MA (2006) The elusive gold standard: Future perspectives for HIV adherence assessment and intervention. J Acquir Immune Defic Syndr 43: S149-S155.
12. Schaecher KL (2013) The importance of treatment adherence in HIV. Am J Manag Care 19: s231-7.

13. Cohen GM (2007) Access to diagnostics in support of HIVIAIDS and tuberculosis treatment in developing countries. AIDS 21: S81-S87.

14. Watt MH, Maman S, Golin CE, Earp JA, Eng E, et al. (2010) Factors associated with self-reported adherence to antiretroviral therapy in a Tanzanian setting AIDS care 22: 381-389.

15. Weaver ER, Pane M, Wandra T, Windiyaningsih C, Samaan G (2014) Factors that influence adherence to antiretroviral treatment in an urban population, Jakarta, Indonesia. PLOS one 9: e107543.v

16. Hegazi A, Bailey RL, Ahadzie B, Alabi A, Peterson K (2010) Literacy, education and adherence to antiretroviral therapy in The Gambia. Aids Care 22: 1340-1355.

17. http://www.handsoncare.gm/

18. Oku AO, Owoaje ET, Ige OK, Oyo-ita A (2013) Prevalence and determinants of adherence to HAART amongst PLHIV in a tertiary health facility in south-south Nigeria. BMC infectious diseases 13: 401

19. Letta S, Demissie A, Oljira L, Dessie Y (2015) Factors associated with adherence to Antiretroviral Therapy (ART) among adult people living with HIV and attending their clinical care, Eastern Ethiopia. BMC international health and human rights 15: 33 .

20. Gare J, Kelly-Hanku A, Ryan CE, David M, Kaima P, et al. (2015) Factors influencing antiretroviral adherence and virological outcomes in people living with HIV in the highlands of Papua New Guinea. PLoS One 10: e0134918.

21. Teshome W, Belayneh M, Moges M, Endriyas M, Mekonnen E, et al. (2015) Who takes the medicine? Adherence to antiretroviral therapy in southern ethiopia. Patient Prefer Adherence 9: 1531.

22. Nozaki I, Dube C, Kakimoto K, Yamada N, Simpungwe JB (2011) Social factors affecting ART adherence in rural settings in Zambia. AIDS Care 23: 831-838.

23. Fong OW, Ho CF, Fung LY, Lee FK, Tse WH, et al. (2003) Determinants of adherence to highly active antiretroviral therapy (HAART) in Chinese HIVIAIDS patients. HIV medicine 4: 133-138.

24. Pahari S, Roy S, Mandal A, Kuila S, Panda S (2015) Adherence to anti-retrovira therapy \& factors associated with it: A community based cross-sectional study from West Bengal, India. The Indian journal of medical research 142: 301.

25. Suleiman IA, Momo A (2016) Adherence to antiretroviral therapy and its determinants among persons living with HIVIAIDS in Bayelsa state, Nigeria. Pharm Pract (Granada) 14: 631.

26. Yaya I, Landoh DE, Saka B, Wasswa P, Aboubakari AS, et al. (2014) Predictors of adherence to antiretroviral therapy among people living with HIV and AIDS at the regional hospital of Sokodé, Togo. BMC public health 14: 1308.

27. Uzochukwu BS, Onwujekwe OE, Onoka AC, Okoli C, Uguru NP, et al. (2009) Determinants of non-adherence to subsidized anti-retroviral treatment in southeast Nigeria. Health policy and planning 24: 189-196.

28. Pinheiro CA, de-Carvalho-Leite JC, Drachler ML, Silveira VL (2002) Factors associated with adherence to antiretroviral therapy in HIVIAIDS patients: A cross-sectional study in Southern Brazil. Brazilian Journal of Medical and Biological Research 35: 1173-1181. 